\title{
Preparation of Integrated Oxygen Permeable Membranes with a Porous Layer by Partial Reduction Process
}

\author{
Hiroo Takahashi* and Hitoshi Takamura \\ Department of Materials Science, Graduate School of Engineering, Tohoku University, Sendai 980-8579, Japan
}

\begin{abstract}
An oxygen permeable membrane based on mixed oxide-ion and electronic conduction is a promising material for hydrogen production from methane at high temperatures. To increase an oxygen permeation flux, decreasing in thickness is required. In this study, integrated oxygen permeable membranes supported on a porous layer was prepared by partial reduction of dense composite materials. The dense samples of $\left(\mathrm{ZrO}_{2}-\right.$ $\left.3 \mathrm{~mol} \% \mathrm{Y}_{2} \mathrm{O}_{3}\right)-x$ vol\% $\mathrm{NiFe}_{2} \mathrm{O}_{4}(x=33,40,50)$ were prepared by sintering at $1400^{\circ} \mathrm{C}$ under air for $5 \mathrm{~h}$. The one side of the sample was reduced at a temperature range of 800 to $1000^{\circ} \mathrm{C}$ under $\mathrm{Ar}-5 \% \mathrm{H}_{2}$. The microstructure and oxygen flux density were analyzed by using a scanning electron microscopy and a quadrupole mass spectroscopy, respectively. An integrated oxygen permeable membrane of $\left(\mathrm{ZrO}_{2}-3 \mathrm{~mol}_{2} \mathrm{Y}_{2} \mathrm{O}_{3}\right)$ $50 \mathrm{vol} \% \mathrm{NiFe}_{2} \mathrm{O}_{4}$ having a dense layer of $200 \mu \mathrm{m}$ and a porous layer of $300 \mu \mathrm{m}$ was successfully prepared. The oxygen flux density of the membrane was found to be $4.3-7.4 \times 10^{-7} \mathrm{~mol} \cdot \mathrm{cm}^{-2} \cdot \mathrm{s}^{-1}$. [doi:10.2320/matertrans.MBW200802]
\end{abstract}

(Received October 20, 2008; Accepted December 24, 2008; Published February 12, 2009)

Keywords: oxygen permeable ceramics, porous substrate, yttria stabirized zirconia, composites, nickel ferrite

\section{Introduction}

The partial oxidation of methane by using an oxygen permeable membrane is a promising technique for hydrogen production. ${ }^{1)}$ The oxygen permeable membrane requires a high oxygen flux density. To date, perovskite-type oxides such as $\left(\mathrm{Ba}_{0.5} \mathrm{Sr}_{0.5}\right)\left(\mathrm{Co}_{0.8} \mathrm{Fe}_{0.2}\right) \mathrm{O}_{3-\delta}, \quad\left(\mathrm{La}_{0.7} \mathrm{Sr}_{0.3}\right)\left(\mathrm{Ga}_{0.6^{-}}\right.$ $\left.\mathrm{Fe}_{0.4}\right) \mathrm{O}_{3-\delta}$ have been developed. ${ }^{2,3)}$ In our group, $\left(\mathrm{Pr}_{0.7^{-}}\right.$ $\left.\mathrm{Sr}_{0.3}\right)\left(\mathrm{Fe}_{0.8} \mathrm{Al}_{0.2}\right) \mathrm{O}_{3-\delta}$ and $\left(\mathrm{La}_{0.5} \mathrm{Ba}_{0.3} \mathrm{Sr}_{0.2}\right)\left(\mathrm{Fe}_{0.6} \mathrm{In}_{0.4}\right) \mathrm{O}_{3-\delta}$ have been also developed to exhibit a high oxygen flux density of $8-11 \times 10^{-6} \mathrm{~mol} \cdot \mathrm{cm}^{-2} \cdot \mathrm{s}^{-1}$ at $1000^{\circ} \mathrm{C}$ for a thickness of $160-200 \mu \mathrm{m}$, respectively. ${ }^{4,5)}$ In addition to those single-phase-type materials, dual-phase-type membranes such as $\left(\mathrm{Ce}_{0.85} \mathrm{Sm}_{0.15}\right) \mathrm{O}_{2-\delta}-15$ vol\% $\mathrm{MnFe}_{2} \mathrm{O}_{4}$ showing high oxygen flux density and good chemical stability have been reported. ${ }^{5-10)}$ To further improve the oxygen flux density, the preparation of integrated oxygen permeable membrane where a thinner membrane is supported on a mechanically tough porous substrate appears to be effective. ${ }^{11)}$

Oxygen permeable membranes also suffer from degradation due to use under oxygen partial pressure gradient, $\nabla p \mathrm{O}_{2}$, across the membrane as shown in Fig. 1. Basically, the membrane materials should be chemically stable under the $p \mathrm{O}_{2}$ gradient; however, under an operating condition, actual $p \mathrm{O}_{2}$ on fuel side $\left(P 1^{\prime}\right)$ is higher than nominal $p \mathrm{O}_{2}$ determined by gas composition. This difference in actual and nominal $p \mathrm{O}_{2}$ on the fuel side strongly depends on surface activity and the thickness of gas diffusion barrier layer.

In this study, this difference in actual and nominal $p \mathrm{O}_{2}$ on the fuel side is used to fabricate an integrated oxygen permeable membrane supported on a porous substrate. The dense sample of the mixture of $\mathrm{ZrO}_{2}-3$ mol\% $\mathrm{Y}_{2} \mathrm{O}_{3}$ (3YSZ) and $\mathrm{NiFe}_{2} \mathrm{O}_{4}$ (NFO) is firstly prepared, where $3 \mathrm{YSZ}$ and NFO work as an oxide-ion and an electronic conductors, respectively. The dense membrane is then exposed to a large $\mathrm{pO}_{2}$ gradient at which NFO decomposes. As the decomposition of NFO takes place, a porous layer of 3 YSZ which works as a

*Graduate Student, Tohoku University

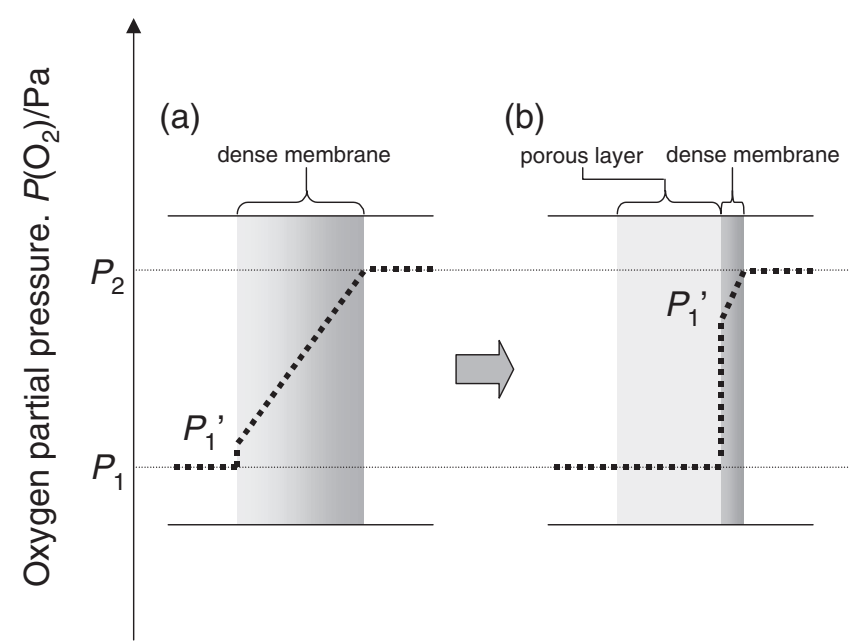

Fig. 1 Schematic diagram of (a) oxygen permeable membrane and (b) membrane supported by porous substrate after partial reduction process.

mechanical support will be formed. Since the porous layer also works as a gas diffusion barrier, at certain thickness, the decomposition of NFO is expected to stop as shown in Fig. 1(b). As a result, the dense 3 YSZ-NFO oxygen permeable membrane supported on the mechanically stable porous 3 YSZ substrate seems to be developed.

The purpose of this study is to prepare 3 YSZ-NFO oxygen permeable membranes on $3 \mathrm{YSZ}$ porous substrate and to study the microstructural change during the reduction process.

\section{Experimental}

$3 \mathrm{YSZ}$ powder $\left(\mathrm{ZrO}_{2}-3 \mathrm{~mol} \% \mathrm{Y}_{2} \mathrm{O}_{3}\right.$; TOSOH Co. $)$ was ball-milled with NFO powder for $24 \mathrm{~h}$. The second phase of NFO was prepared by Pechini method. ${ }^{12)}$ The composition of the mixture was 3 YSZ-33, 40, 50 vol\%NFO. The powder mixture was pressed into disks with dimensions of approximately $\phi 20 \times \mathrm{t} 1.0-1.5 \mathrm{~mm}$, and sintered at $1400^{\circ} \mathrm{C}$ under 

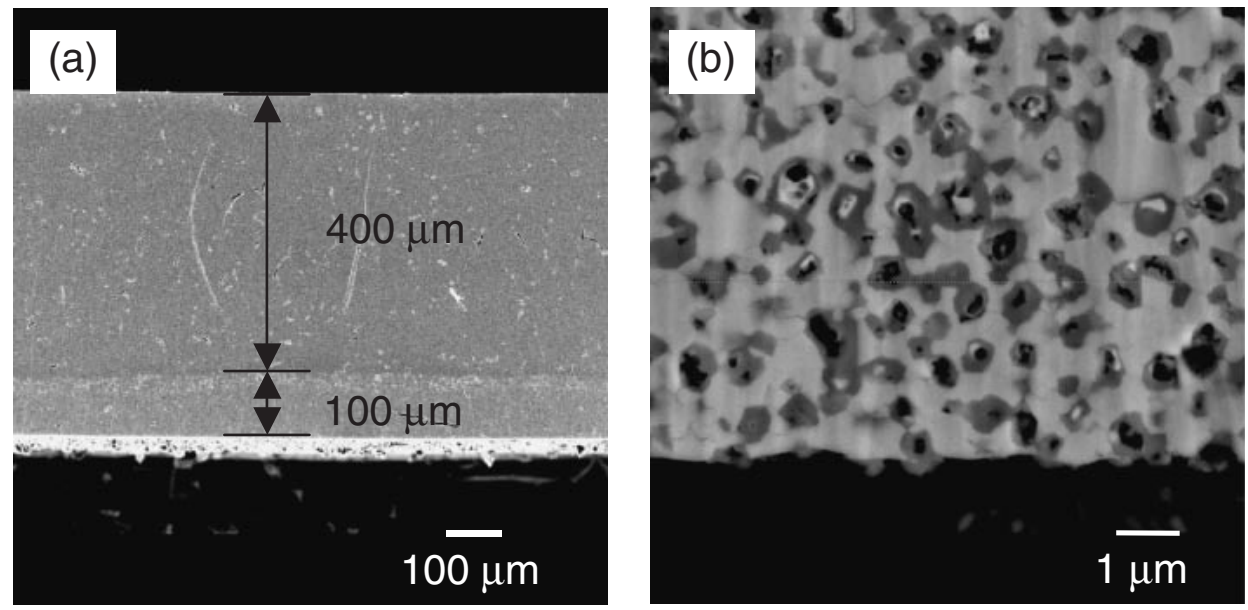

Fig. 2 Cross-sectional SEM images of composite with 40 vol\%NFO after partial reduction process.
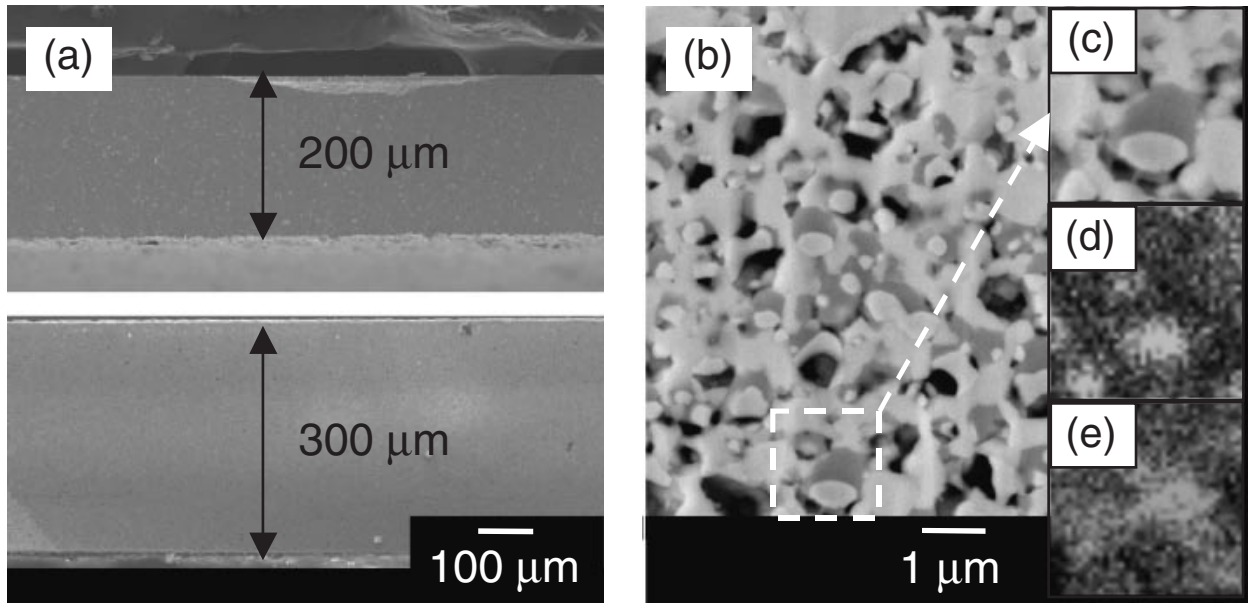

Fig. 3 (a)(b)(c) Cross-sectional SEM images and elemental mapping of (d) nickel and (e) oxygen of composites with 50 vol\%NFO after partial reduction process.

air for $5 \mathrm{~h}$. The dense sample was then exposed to $p \mathrm{O}_{2}$ gradient between $\mathrm{Ar}-5 \% \mathrm{H}_{2}(250 \mathrm{sccm})$ and air $(200 \mathrm{sccm})$ at $800^{\circ} \mathrm{C}$ for 4.5 and $10 \mathrm{~h}$. The oxygen permeability was monitored by a quadrupole mass spectrometer under the same atmospheres at 800 and $1000^{\circ} \mathrm{C}$. After the measurement of oxygen permeability, the disk was cut by using a low speed cutter, and the surface was polished by using a cross-section polisher (JEOL SM-09020). The microstructure before and after the oxygen permeation was observed by using a scanning electron microscope (SEM). All the photographs were taken by a back-scattering electron mode. In addition, elemental mapping was performed.

\section{Results and Discussion}

The 3YSZ-33, 40 and 50 vol\%NFO after sintering showed a relative density of 92 to $94 \%$. The samples having a thickness of approximately 500 and $800 \mu \mathrm{m}$ were used for oxygen permeation test. The microstructure of samples after the oxygen permeation test at $800^{\circ} \mathrm{C}$ for $4.5 \mathrm{~h}$ was observed by using an SEM. Figures 2 and 3 show the cross-sectional SEM images of 3YSZ-40 and 50 vol\%NFO, respectively. For 3 YSZ-33 vol\%NFO, no microstructural change was observed. As shown in Figs. 2(b) and 3(b), the composites with 40 and $50 \mathrm{vol} \% \mathrm{NFO}$ were found to have a porous layer developed from low $\mathrm{pO}_{2}$ side. For the 40 vol\% NFO sample, the thickness of reduced layer was approximately $100 \mu \mathrm{m}$. This thickness was almost same as that of sample with a larger initial thickness. It should be also noted that the reduction seems to be started from the central part of NFO; pores can be seen in the NFO phase. In the case of $50 \mathrm{vol} \%$ NFO, a dense membrane with a thickness of $200 \mu \mathrm{m}$ on the porous substrate with a thickness of $300 \mu \mathrm{m}$ was prepared. Figures 3(d) and (e) show elemental mapping of nickel and oxygen corresponding to Fig. 3(c). Even though NFO was reduced from low $\mathrm{pO}_{2}$ side, $\mathrm{Ni}$ metals were precipitated in central part of NFO. The dense and porous layer thicknesses were almost same as those of samples reduced for longer period of time $(10 \mathrm{~h})$. This implies that $p \mathrm{O}_{2}$ gradient developed across the membranes and the partial reduction process reached an equilibrium state within $4.5 \mathrm{~h}$.

As shown in Fig. 4, the oxygen flux density was measured for $50 \mathrm{vol} \% \mathrm{NFO}$ samples at $1000^{\circ} \mathrm{C}$ under $p \mathrm{O}_{2}$ gradient between $\mathrm{Ar}-5 \% \mathrm{H}_{2}(250 \mathrm{sccm})$ and air $(200 \mathrm{sccm})$. The samples were dense membranes with a thickness of approximately 200 (sample I) and $500 \mu \mathrm{m}$ (sample II), and $4.5 \mathrm{~h}-$ reduced one (sample III) having a $200 \mu \mathrm{m}$-thick dense part and a $300 \mu \mathrm{m}$-thick porous layer. The oxygen flux density for 


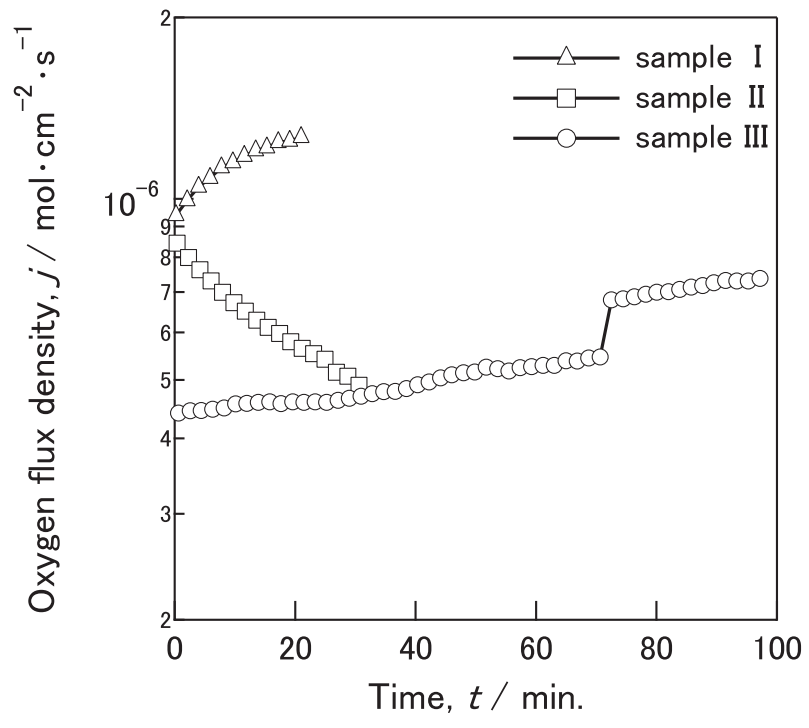

Fig. 4 Oxygen flux density as a function of time for the $200 \mu \mathrm{m}$-thick and $500 \mu$ m-thick dense membrane (Sample I and II, respectively) and the sample prepared by using a partial reduction process (Sample III).

the sample III was limited to 4.3 to $7.4 \times 10^{-7} \mathrm{~mol} \cdot \mathrm{cm}^{-2} \cdot \mathrm{s}^{-1}$ at $1000^{\circ} \mathrm{C}$. Since the oxygen flux density of the sample III was almost equal to that of the sample II, it seems that the effective thickness of the sample III is close to $500 \mu \mathrm{m}$, which is almost same as the initial thickness. On the other hand, compared with samples I and II, the sample III can stand for longer period by a factor of five with respect to durability. The dense membrane samples of I and II were shortly broken after 15 to 20 minutes.

Based on these results, the behavior of partial reduction process will be discussed. The surface oxygen exchange reaction of dual-phase-type membrane such as 3YSZ-NFO takes place at triple phase boundaries (TPBs) comprising of 3 YSZ, NFO and oxygen gas. In this case, the oxygen partial pressure in the vicinity of TPBs may be higher than that of NFO interior. The interior part of NFO in the composites of 40 and $50 \mathrm{vol} \% \mathrm{NFO}$, therefore, should be firstly reached to enough low $p \mathrm{O}_{2}$ at which NFO decomposes as shown in Fig. 5. In addition, the exterior part of NFO touching to $3 \mathrm{YSZ}$, especial high $p \mathrm{O}_{2}$ side, should have higher $p \mathrm{O}_{2}$ than that for the central part of NFO. As a result, a metallic Ni phase seems to be observed in the central part of NFO particles. In other words, as shown in Fig. 5, even though the porous layer can be formed as expected, the effective thickness, which controls the oxygen flux density, does not seem to change. However, the porous layer formed can work to relax stresses induced by reduction and morphological change; as a result, extended durability was observed.

To prepare an optimum integrated structure having a thinner dense 3YSZ-NFO membranes on 3YSZ porous substrates, optimization of morphology of dual-phase composites and reduction conditions including $\mathrm{pO}_{2}$ of oxygen feed side seems to be required.

\section{Conclusions}

The preparation and oxygen permeation properties of $\mathrm{ZrO}_{2}-3$ mol $\% \mathrm{Y}_{2} \mathrm{O}_{3}-x$ vol $\% \mathrm{NiFe}_{2} \mathrm{O}_{4}$ composites, where $x=$

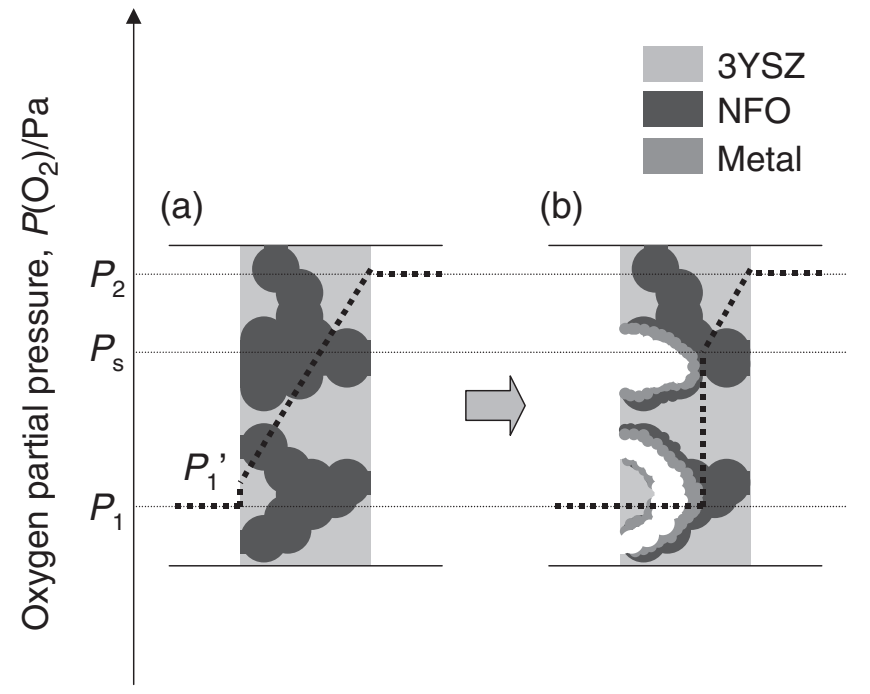

Fig. 5 Schematic diagram of 3YSZ-50 vol\%NFO samples (a) before and (b) after partial reduction process.

33, 40 and 50, have been investigated. The oxygen permeable membrane with a thickness of $200 \mu \mathrm{m}$ supported on a porous substrate was successfully fabricated from a dense $500 \mu \mathrm{m}$ thick $\mathrm{ZrO}_{2}-3 \mathrm{~mol} \% \mathrm{Y}_{2} \mathrm{O}_{3}-50$ vol\% $\mathrm{NiFe}_{2} \mathrm{O}_{4}$ at $800^{\circ} \mathrm{C}$ under $p \mathrm{O}_{2}$ gradient of $\mathrm{Ar}-5 \% \mathrm{H}_{2}$ and air. The oxygen flux density of the sample having an integrated structure was limited to 4.3 to $7.4 \times 10^{-7} \mathrm{~mol} \cdot \mathrm{cm}^{-2} \cdot \mathrm{s}^{-1}$, which is almost comparable to that of $500 \mu \mathrm{m}$-thick dense membrane. On the other hand, the sample having an integrated structure can stand for longer period by a factor of five with respect to durability, compared to conventional dense membranes.

\section{Acknowledgement}

This work was supported in part by Industrial Technology Research Grant Program of The New Energy and Industrial Technology Development Organization (NEDO) of Japan.

\section{REFERENCES}

1) P. N. Dyer, R. E. Richards, S. L. Russek and D. M. Taylor: Solid State Ionics 134 (2003) 21-23.

2) Z. Shao, H. Dong, G. Xiong, Y. Cong and W. Yang: J. Membr. Sci. 183 (2001) 181-192.

3) T. Ishihara, Y. Tsuruta, T. Todaka, H. Nishiguchi and Y. Takita: Solid State Ionics 152-153 (2002) 709-714.

4) H. Takamura, K. Enomoto, Y. Aizumi, A. Kamegawa and M. Okada: Solid State Ionics 175 (2004) 379-382.

5) H. Takamura, Y. Aizumi, A. Kamegawa and M. Okada: J. Fuel Cell Sci. Tech. 3 (2006) 741-748.

6) H. Takamura, K. Okumura, Y. Koshino, A. Kamegawa and M. Okada: J. Electroceram. 13 (2004) 613-618.

7) H. Takamura, T. Kobayashi, T. Kasahara, A. Kamegawa and M. Okada: J. Alloy. Compds. 408-412 (2006) 1084-1089.

8) H. Takamura, H. Sugai, M. Watanabe, T. Kasahara, A. Kamegawa and M. Okada: J. Electroceram. 17 (2006) 741-748.

9) H. Takamura, Y. Koshino, A. Kamegawa and M. Okada: Solid State Ionics 177 (2006) 2185-2189.

10) H. Takamura, M. Ogawa, K. Suehiro, H. Takahashi and M. Okada: Solid State Ionics 179 (2008) 1354-1359.

11) H. Takahashi and H. Takamura: Mater. Trans. 49 (2008) 453-456.

12) M. P. Pechini: U. S. Patent 3330697 (1967). 